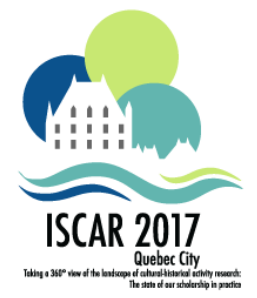

\title{
Concept of Will as an Open Problem in Culture-Historical Context
}

\author{
Nataliya N. Tolstykh \\ Moscow State University of Psychology and Education \\ Moscow, Russia
}

\begin{abstract}
Outlines a new approach to the problem of development of will, emanating from the tradition of thought represented by Vygotsky and Bozhovich. The main conceptual development lies in drawing a distinction between two concepts - will (volya) and goal appropriation, self-regulation, executive cognitive control of behavior (proyzvolnost'). Both concepts emphasize the readiness and ability of an individual to pursue a goal. The distinction lies in the nature of that goal determination. In will, it is self generated and comes from the inner world of the individual while in goal appropriation, it is determined by an external source but is readily appropriated. A such distinction is supported by recent findings in neuroscience which describe the actualization of different brain structures depending on whether an individual acts upon will or willingly submission. Hence, the personality development is considered as a process of will development in which will and goal appropriation inter plays and progresses in specific stages paving the way for subjunctivization or becoming a true subject of that culture.
\end{abstract}

Keywords : Personality development; Will; Cultural-historical tradition; Subjectiveness. 
Currently, both in Russia and other countries, interest in the cultural-historical tradition is focused primarily on mental development and tightly related problems, including cognitive development and developing education. However, the personality component of this development is still left in the shadows. A. Leontiev and L. Bozhovich, two closest associates of Vygotsky, developed original personality concepts based on his most prominent ideas. These personality theories remain as relevant and significant for Russian psychology as ever and, more importantly, still hold a potential for further development.

The author of this article spent the first ten years of her professional work at laboratory for personality psychology at Institute of Psychology. At that time it was managed by L. Bozhovich who dedicated last ten years of her life and creative work to this issue.

According to Bozhovich, she herself alongside her colleagues (L. Slavina, M. Naymark and others) continued the line of personality development research started off by Vygotsky. She used the following words to describe the last years of Vygotsky life's findings when he came closest to personality problem: "Vygotsky passed away before he could complete his studies on personality. But in his work, we see enough material for recreating such studies. The last chapter of his academic pursuits was all about developing affect as emotional decompensation and the point when it "meets" the mind - the challenge of emotional development and emerging of higher feelings. It looks like he considered it a key to understanding those specific system formations, that higher mental (psychic) synthesis, which "shall be rightfully called a child's personality", as he described it (L. I. Bozhovich, 2008, p. 359). Bozhovich, during decades of her experimental research, was looking for certain answers: What exactly is that "higher synthesis"? How does it manifest itself? How is it being developed in ontogenesis? All these questions were answered.

Bozhovich, in her definitions of "personality" always emphasized the basic ability of human on their way to becoming a person to "act independently, regardless the circumstances which have direct effect on them (and even challenge such circumstances), driven by their own deliberately taken goals. Such ability reflects proactive rather than responsive behavior type and makes a person a master of their fate and not a slave to the certain circumstances" (L. I. Bozhovich, 2008, p. 322). Notably, in her last works Bozhovich linked such inner freedom to the development of "functional system which in psychology commonly referred to as will" (L. I. Bozhovich, 2008, p. 322). She then concludes that will is not a special psychical function, but is a person's will structure, which can help us understand integrity of a person, that "higher synthesis" Vygotsky wrote about.

Description of will types that in Bozhovich's studies characterize the stages of personality development at different age are of particular interest.

According to Bozhovich the first stage (infancy and early childhood) marks hypobulian (a term introduced by Krechmer) development of will. A strong-willed behavior at this stage is cause by a "natural" need, which makes a child overcome the obstacles getting in a way of the desired goal. A child acts driven by contextually stronger motive. Any obstacles can only be of an external kind. 
Pre-school aged children's behavior is categorized by what Bozhovich calls "involuntary goal appropriation", which makes them ignore their desires and act according to what's "necessary". This is, however, "not due to their ability to consciously control their behavior, but due to the fact that their moral senses have more propulsion than any other motives. This is what allows them to beat competing motives uncontrollably, unaware for children themselves" (L. I. Bozhovich, 2008, p. 340). From this perspective, one can say that the conflict between "I want" and "I shall" in pre-school children experience is in fact the conflict between the two notions of "I want".

In primary school age children develop volitional behavior as such, that very ability to perform a «classic» act of will. At this stage in a strong equally battle, but oppositely directed affective tendencies, a person (not necessarily of a pre-school age, but of the same level of personality development) tends to turn to an inner intellectual strategy, including reasoning, analyzing, considering consequences of an act. It results in propulsion being given to the weaker but more valuable motive. Willful behavior here is performed through conscious control of motivation. It shall be noted, that many books on the subject use this particular example to describe the phenomenon of will.

The ultimate development of will is what Bozhovich called post-volition, which represents such level of will development, when in order to achieve a goal no contradiction of motives happens, no self-compulsion or any other typical aspects of violation behavior in common definition of "will". In one of her works she would give the term a more poetic description as "inception of a perfect intention".

Illustrating the last stage in volition development, Bozhovich clams that "it emerges as a result of interiorisation of behavior control and shaping other higher psychical systems, representing enough propulsion within themselves to make a person act by will directly, past conscious self-direction. At this stage behavior starts to appear as involuntarily, irrational even. Thus, a person can rush to recue someone is a lethal danger or risk all for something he stands for. This is a "post-volition" as we call it" (L. I. Bozhovich, 2008, p. 362).

Post-volition marks the advanced level of personality development. It can only coexist with harmonic mature personality structure, having strong moral compass, higher emotional education, set of lofty principles, etc. These conditions are essential to consider free choice an "easy task". You make up your mind and nothing can stop you from within to act on it. The harmonic personality structure is the key factor which Bozhovich links to unambiguity of two principal motivation levels: one stands for conscious and voluntary behavior, and another is responsible for involuntary, impulsive, irrational type of behavior.

In this respect, I would like to quote Alexander Zaporozhets, yet another academic from the close circle of Vygotsky's allies, who wrote: "It's common to complain that rational intentions and decisions are not practically implemented due to affect. However, we need to remember that human mind, as extraordinarily flexible and endlessly free as it, simply would put us into a great danger if any idea that comes to our mind would instantly stimulate us to action. Instead, the following fact is rather significant and feasible: before 
an idea is supported by propulsion, a rational decision is required to pass a test by affect in relation with what personal meaning such intention holds for the subject in order to satisfy its needs and best interests" (Zaporozhets, 1986, p. 297).

In her works, Bozhovich showed the long way a human being must go through in order to achieve such advanced level of personality development that would allow them to match the stages of their mental freedom to the freedom of their actions and overall behavior. This is what according to her mean "becoming a personality".

But let us focus on the aspect of 'will' more directly. Will was the subject of the last, unfinished study by Bozhovich. Published snippets of the book and articles along with the in-life works by the same author (E. D. Bozhovich, 1995; L. I. Bozhovich, 1995) lead to suggest the following.

Firstly, the idea of "getting one's behavior under control" remain the most important in her works also being veritable refrain in Vygotsky's The history of development of higher psychical functions, which is hardly a surprise.

Secondly, what stands out is the close synonymic relations between the terms "will", "goal appropriation", "volition", "voluntary behavior", which in my opinion does not reflect that subtle and precise definition used by Bozovich in understanding a personality development process together with nuanced description of shaping one's volition and goal appropriation - different types of "will".

In order to solve the problematics of will and goal appropriation, Bozhovich takes Vygotky's logic for detecting the development of higher psychological functions, using the following line of reasoning: Voluntary behavior is a result of intellectual and voluntary processes turning natural psychological function into a higher function. "Voluntary behavior", she says, emerges from mediation of immediate need by mental processing, followed by intellectualization and voluntarization of propulsion in human's behavior. Resulting from these processes are functionalities, such as intentions, decisions, which are no longer needs or thoughts, but rather what we may call violations» (E. D. Bozhovich, 1995, pp. 338-339). According to this logic, we may assume, that hypobulian will, that Bozhovich associated with infancy, is the natural function which serves as a basis for higher psychical function. Providing voluntary behavior, its ultimate extreme represents the ability to post-volition which defines only a person highly advanced in personal development.

Some contemporary Russian authors engaged in cultural-historical tradition (Smirnova, 2015) prefer to draw a distinction between two concepts - will (volya) and goal appropriation, executive cognitive control of behavior (proizvolnost), using them to describe principally different types of behavior and abilities. Supporting this idea as a whole, yet not being entirely supportive about the offered definitions, we still consider this as a rewarding idea (Tolstykh, 2010).

Goal appropriation (self-regulation. executive cognitive control of behavior) can stand for an ability to control one's behavior, act on the conscious intention, to perform a certain 
task, challenge, and use self-compulsion for it, more or less. In this sense, the term means what some international authors call "Victorian will".

Will, on the other hand, is better used to define intentionality coming from inner freedom, an ability to wish fearlessly, set life goals of your own, choose your life's demands and moral values. Another reason for using the term in this particular meaning it that in Russian the word for 'svoboda' (freedom) is tightly related to the word 'volya' (will). As Pushkin wrote "Happy is not what the world has to offer, but peace and will there is" (or maybe another translation "in the world there is no happiness, but there is peace and freedom") and he could hardly mean "Victorian will" as self-compulsion in any form. In modern Russian psychological context, well-understood 'will" is close to the concepts of "subject" and "personality subjectivness".

Proposed distinction of terms "will" and "goal appropriation" can contextually be aligned with ideas voiced by Leshly Ferber, an American psychologist. According to him the current concepts of will do not work because, in fact, there are two phenomenological realities of will which stand so much apart that only a general abstract meaning can be used to unite them (Farber, 1966, p. 7). Other authors share similar views on the subject.

Extra immediacy of the problem arises at seemingly the calmest stage of child development - primary school years. By far the majority of teachers and psychologists agree that this age marks the point where the key role is taken by goal appropriation as ability of putting one's behavior under control and acting in accordance with the regulation of a social institution, namely school, represented principally by a teacher. Nowadays, some nursery teachers in their best intentions practice discipline among younger children, telling them to obey the basic rules such as "sitting still with their hands on the desk". Nursery teachers believe that this skill facilitate child's adaptation to school system where the set of similar external rules and requirement expand ever greater. In any way, it is commonly suggested that both learning and personality development processes at primary school need to be based on voluntary behavior, including self-compulsion. In all fairness, some teachers and psychologists hold contrary opinion, suggesting that primary schools shall allow children to play and use the relative volitional behavior mechanisms. We consider both these views wrong.

In order to sustain our position, we need to look at voluntary behavior in terms of who's setting the goal - the person or somebody for them (a teacher, a parent or any other people). Our opponents see this as irrelevant. But we consider it exactly the thing of crucial importance for a well-formed learning and personality development.

A number of schools across Russia adopted the educational program called "Rostok" introduced by V. Stepanova and described in many publications, e.g. Stepanova and Tolstykh (2016). This work offers educational process which is primarily based on a children's free will. They gradually start to develop a code of behavior and ethics which allows shaping the ability to act voluntarily through self-control defined by setting a goal by themselves. Such process of will development can only exist within a special organization of educa- 
tional system, where synergy-based coordination is provided by every single one in school community.

This method of will development proved to be very successful, resulting in higher creativity in children, their artistic skills and such. Longitudinal neurophysiological studies are another convincing testimony to the feasibility of this method. Comparison of EEG activities in various experimental cases by children, engaged in "Rostok" educational program and children with experiences of traditional learning shows not only the more advanced development of some parts of the brain, but also that such development differs significantly between tested groups (Knyazev et al., 2017).

\section{References}

Bozhovich, E. D. (1995). From notebooks by L. I. Bozhovich: Ideas about will development. In D. Feldstein (Ed.), L.I. Bozhovich shaping a personality (pp. 333-341). Moscow: Institute of Practical Psychology, Voronezh: MODEK Scientific Development and Production Center.

Bozhovich, L. I. (1995). Will development in ontogenesis. In D. I. Feldstein (Ed.), Shaping a personality (pp. 302-332). Institute of Practical Psychology, Voronezh: MODEK Scientific Development and Production Center.

Bozhovich, L. I. (2008). Personality and its formation at the young age. St. Petersburg: Peter.

Farber, L. (1966). The ways of the will: Essays towards a psychology and psychopathology of the will. New York: Basic Book.

Knyazev, G. G., Savostyanov, A. N., Bocharov, A. V., Slobodskaya, H. R., Bairova, N. B., Tamozhnikov, S. S., \& Stepanova, V. V. (2017). Effortful control and resting state networks: A longitudinal EEG study. Neuroscience, 346, 365-381.

Smirnova, E. O. (2015). On the problem of will and self regulation in cultural historical psychology. Kul'turno-istoricheskaya psikhologiya [Cultural-Historical Psychology], 11(3), 9-15.

Stepanova, V. V., \& Tolstykh, N. N. (2016). Interdisciplinary relationships between social, developmental and educational psychology: Resources for development. Social Psychology and Society, 7(1), 23-44.

Tolstykh, N. N. (2010). Hronotop: Kul'tura i ontogenez [Chronotope: Culture and ontogenesis]. Moscow: Smolensk.

Zaporozhets, A. V. (1986). Selected works in psychology, Vol. II. Moscow: Education. 